\title{
Article \\ Effect of Heat Treatment on the Microstructure and Mechanical Properties of Selective Laser-Melted Ti64 and Ti-5Al-5Mo-5V-1Cr-1Fe
}

\author{
Hongjie Bai ${ }^{1,2}$, Hao Deng ${ }^{3}$, Longqing Chen ${ }^{4}$, Xianbo Liu ${ }^{3}$, Xiaorong Qin ${ }^{5}$, Dingguo Zhang ${ }^{1}$, Tong Liu ${ }^{6, *}$ \\ and Xudong Cui ${ }^{3, *}$
}

check for

updates

Citation: Bai, H.; Deng, H.; Chen, L.; Liu, X.; Qin, X.; Zhang, D.; Liu, T.; Cui, X. Effect of Heat Treatment on the Microstructure and Mechanical Properties of Selective Laser-Melted Ti64 and Ti-5Al-5Mo-5V-1Cr-1Fe. Metals 2021, 11, 534. https://doi.org/ $10.3390 /$ met11040534

Academic Editor: Christine Borchers

Received: 7 March 2021

Accepted: 22 March 2021

Published: 25 March 2021

Publisher's Note: MDPI stays neutral with regard to jurisdictional claims in published maps and institutional affiliations.

Copyright: (c) 2021 by the authors. Licensee MDPI, Basel, Switzerland. This article is an open access article distributed under the terms and conditions of the Creative Commons Attribution (CC BY) license (https:/ / creativecommons.org/licenses/by/ $4.0 /)$.
1 School of Science, Nanjing University of Science and Technology, Nanjing 210094, China; baihongjie_1@163.com (H.B.); zhangdg419@mail.njust.edu.cn (D.Z.)

2 Institute of System Engineering, China Academy of Engineering Physics, Mianyang 621900, China

3 Institute of Chemical Materials, China Academy of Engineering Physics, Mianyang 621900, China; denghaoscu@126.com (H.D.); liuxianbowfl@163.com (X.L.)

4 Key Laboratory of Radiation Physics and Technology of Ministry of Education, Institute of Nuclear Science and Technology, Sichuan University, Chengdu 610064, China; chenlongqing@scu.edu.cn

5 Department of Criminal Science and Technology, Sichuan Police College, Luzhou 642400, China; qxr18909089303@163.com

6 Chengdu Science and Technology Development Center, China Academy of Engineering Physics, Chengdu 610200, China

* Correspondence: liut@yinhe596.cn (T.L.); xudcui@163.com (X.C.)

Abstract: Additive manufacturing (AM) has shown the ability in processing titanium alloys. However, due to the unique thermal history in AM, the microstructure of AM-fabricated parts is metastable and non-equilibrium. This work was aiming to tailor the microstructure and to improve the mechanical properties of $\alpha+\beta$ Ti-6Al-4V alloy and metastable $\beta$ Ti-5Al-5Mo-5V-1Cr-1Fe alloys by manipulating the post-process heat treatment. The results showed that Ti-6Al-4V exhibited a metastable $\alpha^{\prime}$ martensite microstructure in the as-fabricated condition, while a metastable $\beta$ structure was formed in as-printed Ti-5Al-5Mo-5V-1Cr-1Fe. After post-process heat treatment, both lamellar and bimodal microstructures were obtained in Ti64 and Ti-5Al-5Mo-5V-1Cr-1Fe alloys. Especially, the Ti-6Al-4V alloy subjected to $950^{\circ} \mathrm{C}$ annealing showed the lamellar structure with the highest fracture toughness of $90.8 \pm 2.1 \mathrm{MPa}^{1 / 2}$. The one cyclically heat-treated has excellent combined strength, ductility and fracture toughness attributed to the bimodal structure. In addition, similar observations of lamellar and bimodal microstructure appeared in the post-process heat-treated Ti-5Al-5Mo-5V-1Cr- $1 \mathrm{Fe}$ alloy. This study demonstrated that heat treatment is an effective way to tackle the non-equilibrium microstructure and improve the mechanical properties of selective laser melting (SLM)-fabricated titanium alloys.

Keywords: additive manufacturing; selective laser melting; titanium alloys; microstructure; mechanical properties

\section{Introduction}

Selective laser melting (SLM) is a promising rapid prototyping technology in producing metallic components and enabling freedom designs with a low material waste [1]. The versatility of SLM has attracted significant interest in manufacturing high-value alloys used in aerospace, automobile and biomedical applications [2,3]. A wide range of SLMfabricated alloys has been investigated, such as titanium alloys [4,5], aluminum alloys [6,7] and steels $[8,9]$, with emphasis on processing parameter optimization, microstructure manipulation and mechanical properties improvement.

Among the above materials, titanium alloys, including both $\alpha+\beta$ Ti-alloys and metastable $\beta$ Ti-alloys, have been processed by SLM. However, similar to the welding 
process, SLM-fabricated Ti-alloys go through the repeated melting/solidifying process, in which the metallic powder is fused by a laser source layer by layer. Consequently, the epitaxial growth is promoted, resulting in columnar $\beta$ grains with a $<100>$ fiber texture along the building direction $[10,11]$. In addition, the extremely high solidification rate $\left(>10^{3}{ }^{\circ} \mathrm{C} / \mathrm{s}\right)$ in molten pool causes a non-equilibrium phase transformation [12]. For instance, $\beta \rightarrow \alpha^{\prime}$ shear transformation takes place during the SLM fabrication of Ti-6Al-4V (Ti64) alloy [13], and a metastable $\beta$ structure was formed in Ti-5Al-5Mo-5V-3Cr [14] and Ti-5Al-5Mo-5V$3 \mathrm{Cr}-1 \mathrm{Zr}$ [15]. Therefore, the as-fabricated $\alpha+\beta$ and metastable $\beta$ Ti-alloys possess poor mechanical properties, including mechanical anisotropy, low ductility and batch inconsistency. Undoubtedly, these unreliable microstructures and mechanical properties may not meet the standards for aerospace applications.

Titanium alloys are able to present various microstructures by different heat treatments, which are critical in controlling the microstructure and mechanical properties of SLM-prepared titanium alloys. The heat treatment process is useful in relieving the residual stress and tailoring the microstructure. It is well accepted that the lamellar microstructure generally comes with a high fracture toughness and high resistance to fatigue crack propagation, while the one with a bimodal structure usually possess an excellent combination of strength and ductility [16,17]. For Ti64, heat treatment is able to decompose martensite structures and convert them into an $\alpha+\beta$ structure so that the ductility is improved. Cao et al. [18] studied the decomposing mechanism of martensite during the heat treatment process. Zhang et al. [19] and Vrancken et al. [20] investigated the Ti64 alloys annealed below the transus temperature and obtained lamellar microstructure with different sizes of $\alpha$ phase. A novel bimodal structure was obtained in SLM-fabricated Ti64 by Sabban et al. [21] by a cyclic annealing process. Deng et al. [15] proposed three typical heat treatment strategies to realize bimodal and bi-lamellar structures in metastable SLM-prepared Ti55531 alloys. Carlton et al. [22] clarified the effect of different heat treatment temperatures on the morphology and size of $\alpha$ phase as well as the corresponding mechanical performance of Ti5553 alloys. The above studies indicate that the non-equilibrium phases in SLM-fabricated titanium alloys can be transformed by post-process heat treatment, which improve the mechanical properties in turn.

Among a variety of the aeronautical Ti-alloys, Ti64 alloy, which is one of the most widely used commercial $\alpha+\beta$ Ti-alloys in the aviation industry, has excellent performance in various aspects [23]. In addition, the famous Russian Ti-alloy, Ti-5Al-5Mo-5V-1Cr-1Fe (Ti55511), is a robust metastable Ti-alloy with high fracture toughness and strength to be employed in aerospace applications, such as linkage units and landing gear [24]. SLM shows a great potential in manufacturing Ti-alloys parts with complex geometry. Given that Ti64 and Ti55511 are respectively typical $\alpha+\beta$ and metastable $\beta$ titanium alloys, the further investigation into SLM-fabricated Ti64 and Ti55511 is essential and highly desired. Therefore, the microstructures of SLM-fabricated Ti64 and Ti55511 are systematically studied in this work. In order to further improve the mechanical property of SLM-fabricated Ti alloys, especially the tensile property and fracture toughness, a series of heat treatments were conducted to tailor the microstructure of SLM-fabricated Ti64 and Ti55511 alloys. The effects of heat treatment on the microstructure evolution and resultant mechanical property were systematically investigated.

\section{Materials and Methods}

The Ti64 and Ti55511 spherical powders were prepared by electrode induction meltinggas atomization (EIGA 50-500, ALD Vacuum Technologies, Hanau, Germany). The chemical composition of Ti64 and Ti55511 powders is listed in Table 1, which is measured by inductively coupled plasma optical emission spectrometry (ICP-OES, Agilent 725, USA) and elemental analyzer (TC-400, LECO, St Joseph, MI, USA). Particle size distribution results show that the powder size of both Ti64 and Ti55511 ranges between 10 and $55 \mu \mathrm{m}$, as shown in Figure 1a,c. Scanning electron microscope (SEM) images show an excellent spherical morphology of Ti64 and Ti55511 powders (Figure 1c,d). 
Table 1. Chemical composition (wt \%) of the spherical powders.

\begin{tabular}{ccccccccccc}
\hline Alloy & Ti & Al & V & Mo & Cr & Fe & $\mathbf{C}$ & $\mathbf{N}$ & O & H \\
\hline Ti64 & Bal & 5.95 & 4.10 & - & - & 0.19 & 0.04 & 0.01 & 0.12 & 0.008 \\
Ti55511 & Bal & 4.89 & 4.86 & 4.91 & 0.96 & 1.01 & 0.04 & 0.02 & 0.14 & 0.009 \\
\hline
\end{tabular}
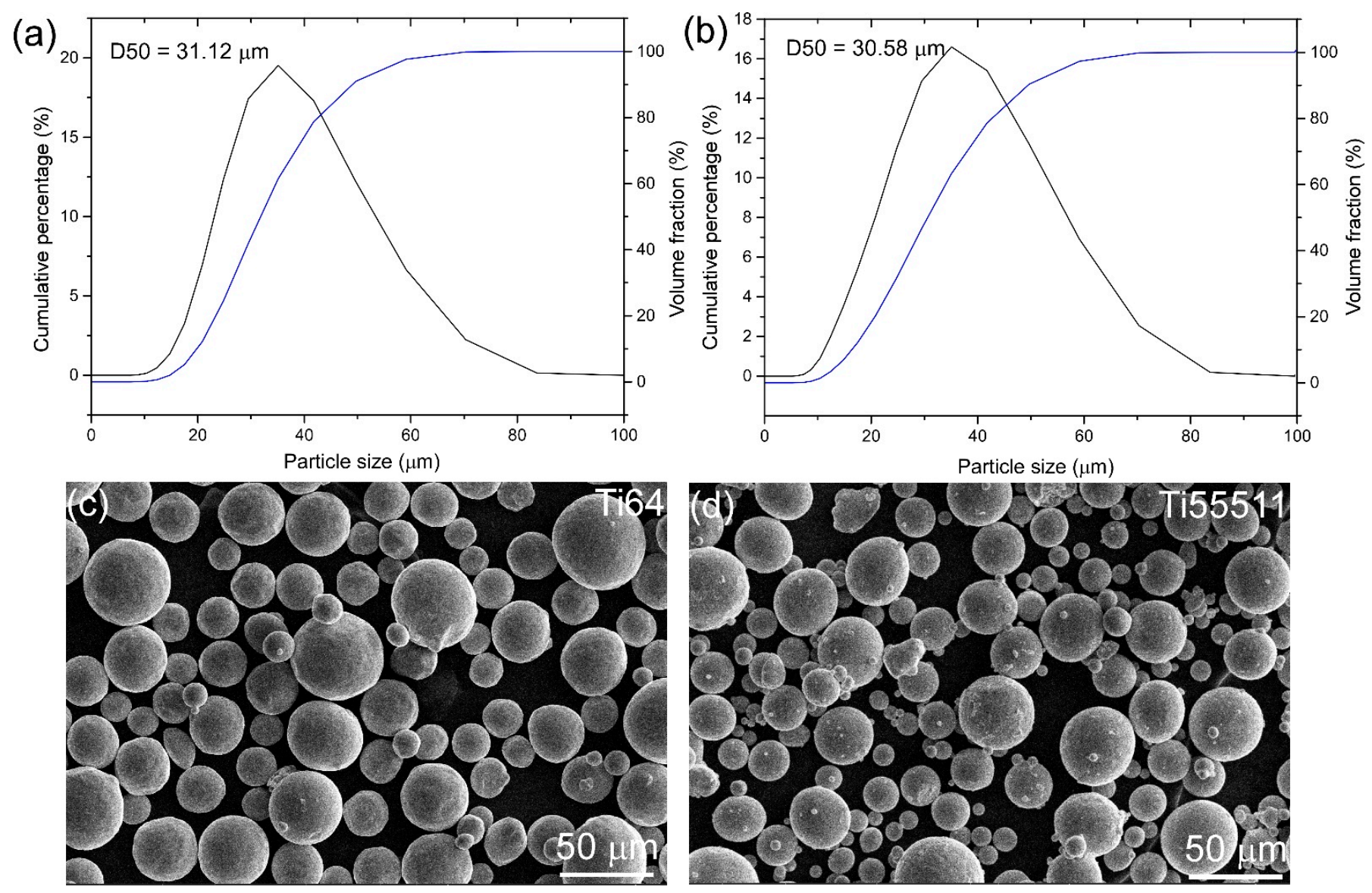

Figure 1. Particle size distribution of (a) Ti64 and (b) Ti55511. SEM images showing the morphology of powder for (c) Ti64 and (d) Ti55511.

Both Ti64 and Ti55511 cuboid samples with size of $70 \times 25 \times 70 \mathrm{~mm}^{3}$ were fabricated by using an EOS M290 machine (EOSINT, Germany). The processing parameters for Ti64 alloy were set as follows: laser power was $280 \mathrm{~W}$, hatch spacing was $110 \mu \mathrm{m}$, layer thickness was $30 \mu \mathrm{m}$ and scanning speed was $1400 \mathrm{~mm} / \mathrm{s}$. For the fabrication of Ti55511 alloy, the laser power was $240 \mathrm{~W}$, hatch spacing was $90 \mu \mathrm{m}$, layer thickness was $30 \mu \mathrm{m}$ and scanning speed was $1250 \mathrm{~mm} / \mathrm{s}$. A stripe scanning strategy was employed for both Ti64 and Ti55511. Under these parameter combinations, the relative density of both Ti64 and Ti55511 can reach up to $99.9 \%$.

To improve the mechanical properties of as-fabricated samples, different heat treatments were conducted for Ti64 and Ti55511. The $\beta$ transus temperature $\left(\mathrm{T}_{\beta}\right)$ of Ti64 and Ti55511 alloys measured by the metallographic observation method were 990 and $870{ }^{\circ} \mathrm{C}$, respectively (metallographic method determining the $\beta$ transus includes microscopic observation of phases present in heat-treated and quenched samples from the temperatures below and above $\beta$ transus). For Ti-alloy, lamellar structure and bimodal structure are the most favorable structures for practical applications. Ti-alloys with lamellar structure have excellent fracture toughness, while bimodal structure enables the outstanding combination of strength and ductility. Sabban et al. [21] and Liu et al. [25] pointed out that cyclic anneal- 
ing (CA) was an effective way to realize bimodal structure in Ti64 alloy. In order to obtain these structures, two kinds of heat treatments including solution at different temperatures followed by furnace cooling (FC) and CA were employed to tailor the microstructure of Ti64, as shown in Figure 2a,b. For metastable Ti-alloy, solution treatment in the $\alpha+\beta$ phase field followed by aging at lower temperatures $(\alpha \beta$-STA) is a typical method to achieve bimodal structure (Figure 2c). In addition, beta annealing followed by slow cooling and aging (BASCA) is an effective way to obtain lamellar structure owing to the low cooling rate [26]. Therefore, Ti55511 was subjected to $900{ }^{\circ} \mathrm{C}$ (above the $\mathrm{T}_{\beta}$ ) solution treatment, and slowly cooled down to $600{ }^{\circ} \mathrm{C}$ for aging (Figure 2d).
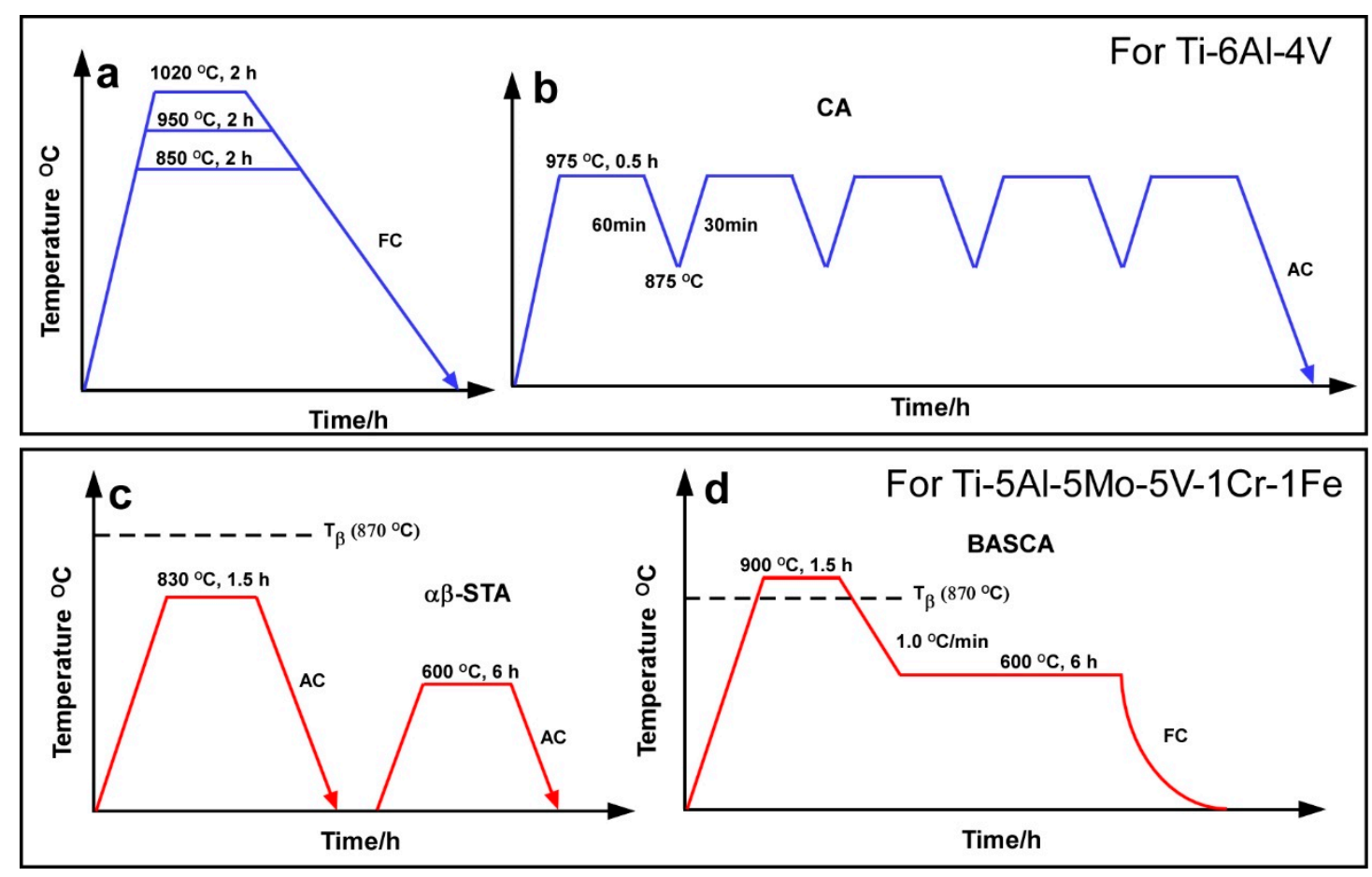

Figure 2. Schematic of post-heat treatment: (a) solution treatment followed by furnace cooling (FC) for Ti64, (b) cyclic annealing (CA) for Ti64 [25], (c) solution treatment in the $\alpha+\beta$ phase field followed by aging ( $\alpha \beta-S T A)$ for Ti55531 and (d) beta annealing followed by slow cooling and aging (BASCA) for Ti55511.

Optical microscopy (OM, Axio Oberver A1m, ZEISS, Germany), scanning electron microscope (SEM, Inspect F50, FEI, Hillsboro, State of Oregon, USA), transmission electron microscopy (TEM, Tecnai G2 F20, FEI, Hillsboro, State of Oregon, USA) and X-ray diffraction (XRD, DX2700, Dandong HaoYuan, Dandong, China; step size of $0.01^{\circ}$ ) were used to analyze the microstructure and phase of Ti64 and Ti55511 alloys. All metallography samples were polished by carborundum ( $\mathrm{SiC}$ )paper up to a 3000\# finish, then etched with Kroll's etchant ( $1 \mathrm{vol} \% \mathrm{HF}+4 \mathrm{vol} \% \mathrm{HNO}_{3}+95 \mathrm{vol} \% \mathrm{H}_{2} \mathrm{O}$ ). TEM samples were prepared by using ion milling (Gatan-PIPS II 695). The tensile tests were performed on a standard M10 cylindrical specimen according to the American Society for Testing and Materials (ASTM )standard E8, as shown in Figure 3a. The loading direction is parallel to the building direction. The tensile strain rate was set as $0.5 \mathrm{~mm} / \mathrm{min}$. Compact-tension specimens $(\mathrm{C}(\mathrm{T}))$ were used to evaluate the fracture toughness $\left(K_{I C}\right)$ with width, $\mathrm{W}$, of $50 \mathrm{~mm}$ and thickness, b, of $12.5 \mathrm{~mm}$, according to the ASTM standard E1820-18. $K_{I C}$ tests were carried out on an MTS Landmark 370.10 machine (MTS, Eden Prairie, Minnesota, USA), as shown in Figure 3b. For each sample, three tests were carried out to obtain an average value of ultimate tensile strength (UTS), yield strength (YS), elongation (EL) and $K_{I C}$. 

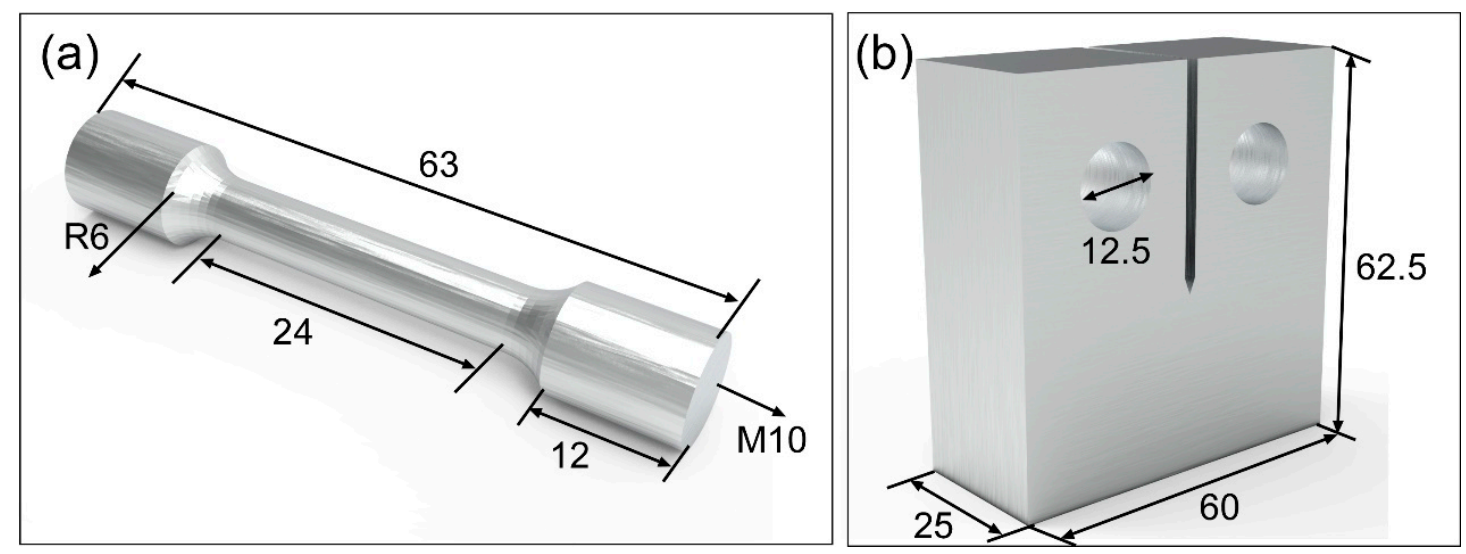

Figure 3. Schematic of (a) standard M10 cylindrical tension test samples and (b) dimension of compact-tension specimen.

\section{Results}

\subsection{The Microstructure and Phase of As-Fabricated Sample}

Figure 4 illustrates the microstructures of as-fabricated Ti64 and Ti55511, with the vertical OM images of Ti64 and Ti55511 shown in Figure 4a,b, respectively. Similar to other SLM-prepared Titanium alloys, columnar prior $\beta$ grains are observed in the vertical side of both samples. In order to further investigate the detailed information about the internal part of prior $\beta$ grains, we employed high-resolution SEM and TEM analyses on Ti64 and Ti55511 samples with the images shown in Figure 4c-f. Apparently, there are $\alpha^{\prime}$ martensite phases inside the Ti64 alloy with $\alpha^{\prime}$ laths randomly embedding inside $\beta$ grains. It has been demonstrated that Ti64 possessed a critical cooling rate of $410^{\circ} \mathrm{C} / \mathrm{s}$, beyond which the formation of $\alpha^{\prime}$ phases would be proceeded [27]. According to a number of studies [12,18], the cooling rate of the SLM method (over $10^{3}{ }^{\circ} \mathrm{C} / \mathrm{s}$ ) is much higher than that of the critical transformation rate of $\alpha^{\prime}$ phases, which explains the existence of $\alpha^{\prime}$ phases in SLM-prepared Ti64 alloys. As for the Ti55511 alloy, only metastable $\beta$ phases are observed rather than $\alpha^{\prime}$ or $\alpha$ phase, as displayed in Figure $4 \mathrm{~d}$,e. It is due to the considerable amount of $\beta$ stabilizers introduced into Ti55511, which is exactly the cases found in SLM-built Ti5553 and Ti55531 alloys [14,15]. As is known to all, the raise of $\beta$ stabilizers into titanium alloys is advantageous for expanding the $\beta$ formation window, improving the chemical stability of $\beta$ phases and suppressing the transition temperature of the martensites [28]. Therefore, the pretty high cooling rate during SLM resembles a quenching process that is quite effective in restraining the precipitation of $\alpha$ and $\alpha^{\prime}$, so metastable $\beta$ phases is observed in Ti55511 alloys. We also notice dendritic structures inside Ti55511 alloys. It is resulted from the constitutional supercooling and the consequent instability occurring in the solidification front during the SLM process of Ti55511 alloys with abundant solute elements [29]. 

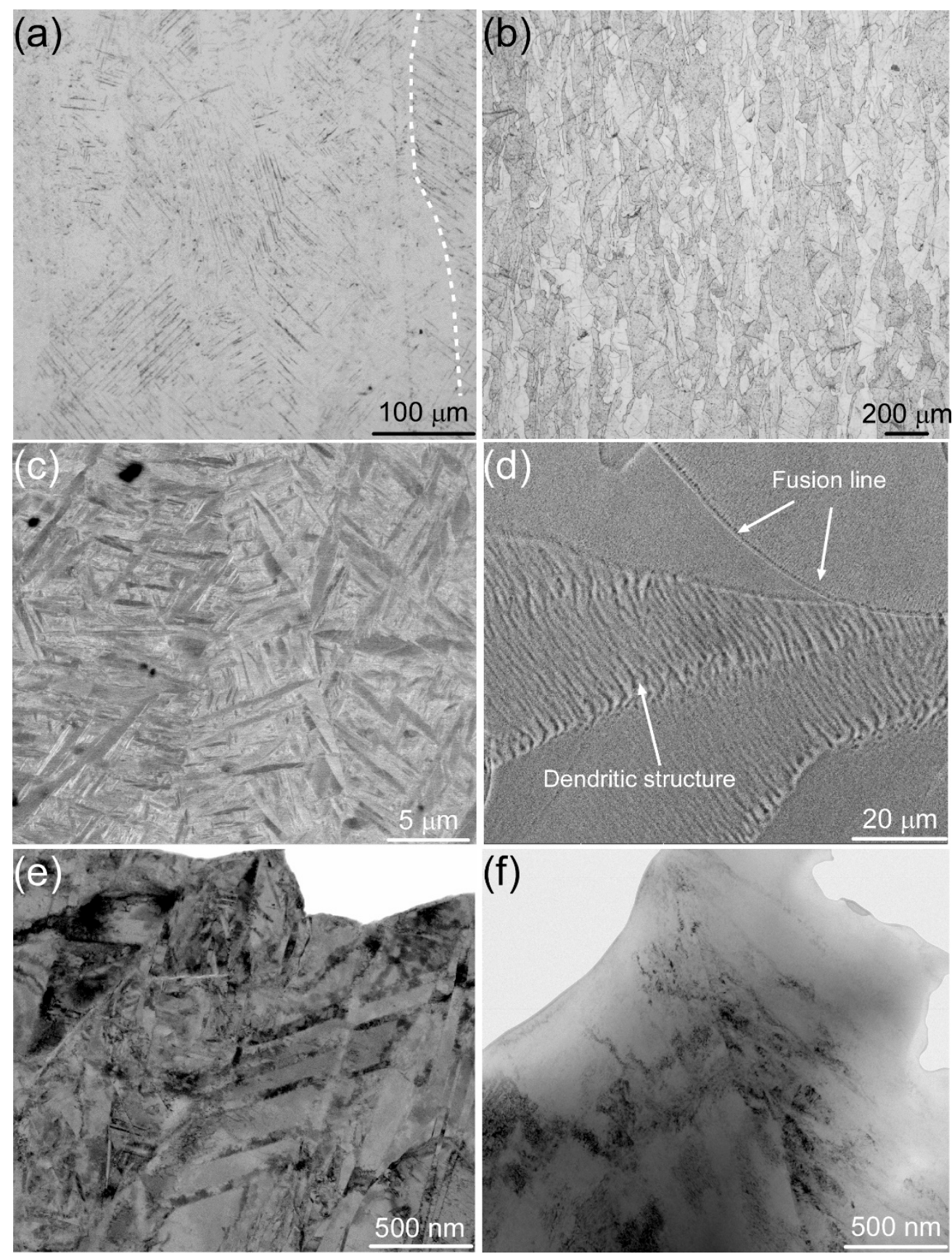

Figure 4. Optical microscopy $(\mathrm{OM})$ images showing the columnar prior $\beta$ grains on the vertical plane of $(\mathbf{a}, \mathbf{b})$ for Ti64 and Ti55511 samples, respectively. (c,d) are the SEM backscattered electron images of Ti64 and Ti55511 samples. (e,f) are the TEM images of Ti64 and Ti55511 samples.

\subsection{The Microstructure and Phase of Heat-Treated Sample}

The XRD patterns of the as-built and heat-treated samples are shown in Figure 5. The $\alpha^{\prime}$ and $\alpha$ diffraction peaks of the SLM-built Ti64 sample almost overlapped each other. The peak belonging to $\beta(110)$ was detected in heat-treated Ti64 samples. Only the diffraction peaks of $\beta$ phase are observed in the SLM-built Ti55511, which is consistent with the results of SEM and TEM. After heat treatment, $\alpha$ phase is recognized in Ti64 without a trace of $\beta$ phase. On the contrary, $\alpha$ phase emerges in the heat-treated Ti55511 alloy together with the original $\beta$ phase. 

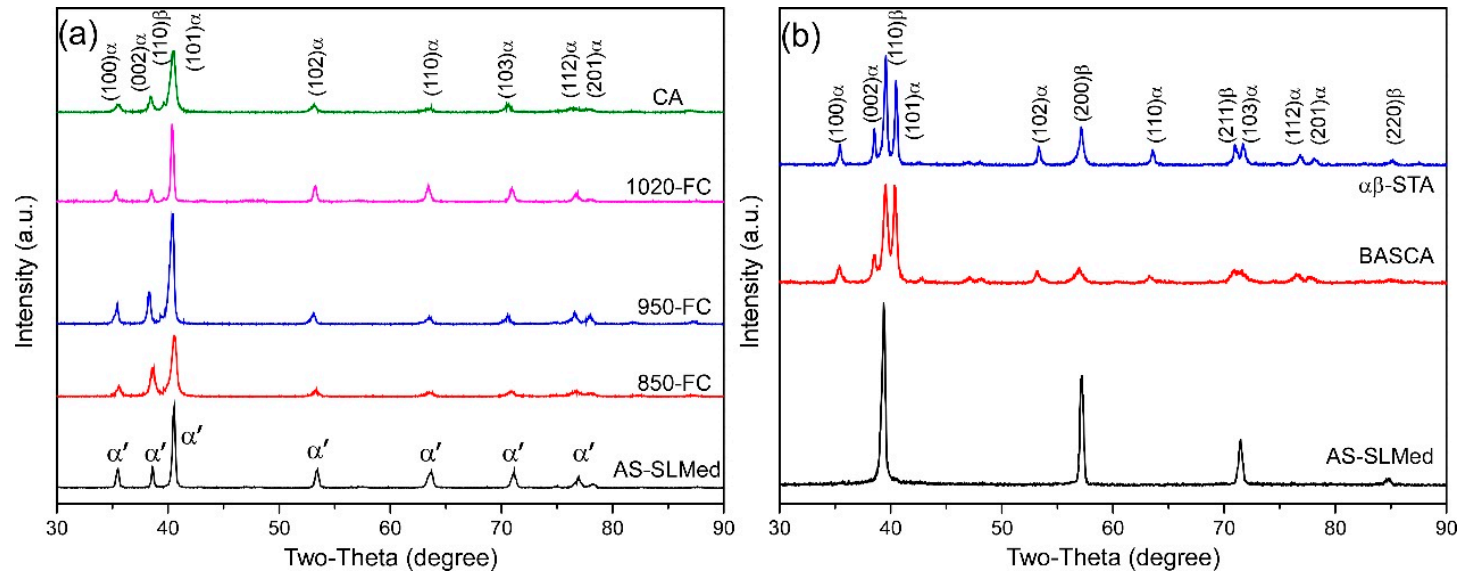

Figure 5. The X-ray diffraction (XRD) spectra of as-fabricated and post-heat treatment samples of (a) Ti64 and (b) Ti55511.

The microstructural features of the Ti64 and Ti55511 samples after heat treatment are further analyzed based on OM and SEM images, as seen in Figures 6 and 7 . The martensite structure in Ti64 alloys entirely transformed to the $\alpha+\beta$ structure after the heat treatment process. According to the OM images captured under different heat treatment conditions (Figure 6), the width of $\alpha$ laths increases with the increment of processing temperature. In detail, the average widths of $\alpha$ laths are 1.6, 3.9 and $21.8 \mu \mathrm{m}$ under 850,950 and $1020{ }^{\circ} \mathrm{C}$, respectively. After the CA treatment, a bimodal structure consisting of large primary $\alpha$ (about $8.7 \mu \mathrm{m}$ in width) and fine secondary $\alpha$ emerged in Ti64 alloys. Further SEM studies demonstrated a typical bimodal $\alpha+\beta$ structure in Ti64 alloys, as shown in Figure 7. We recognize the white features along $\alpha$ phases as retained $\beta$, while fine secondary $\alpha$ phases were also observed in the CA sample.

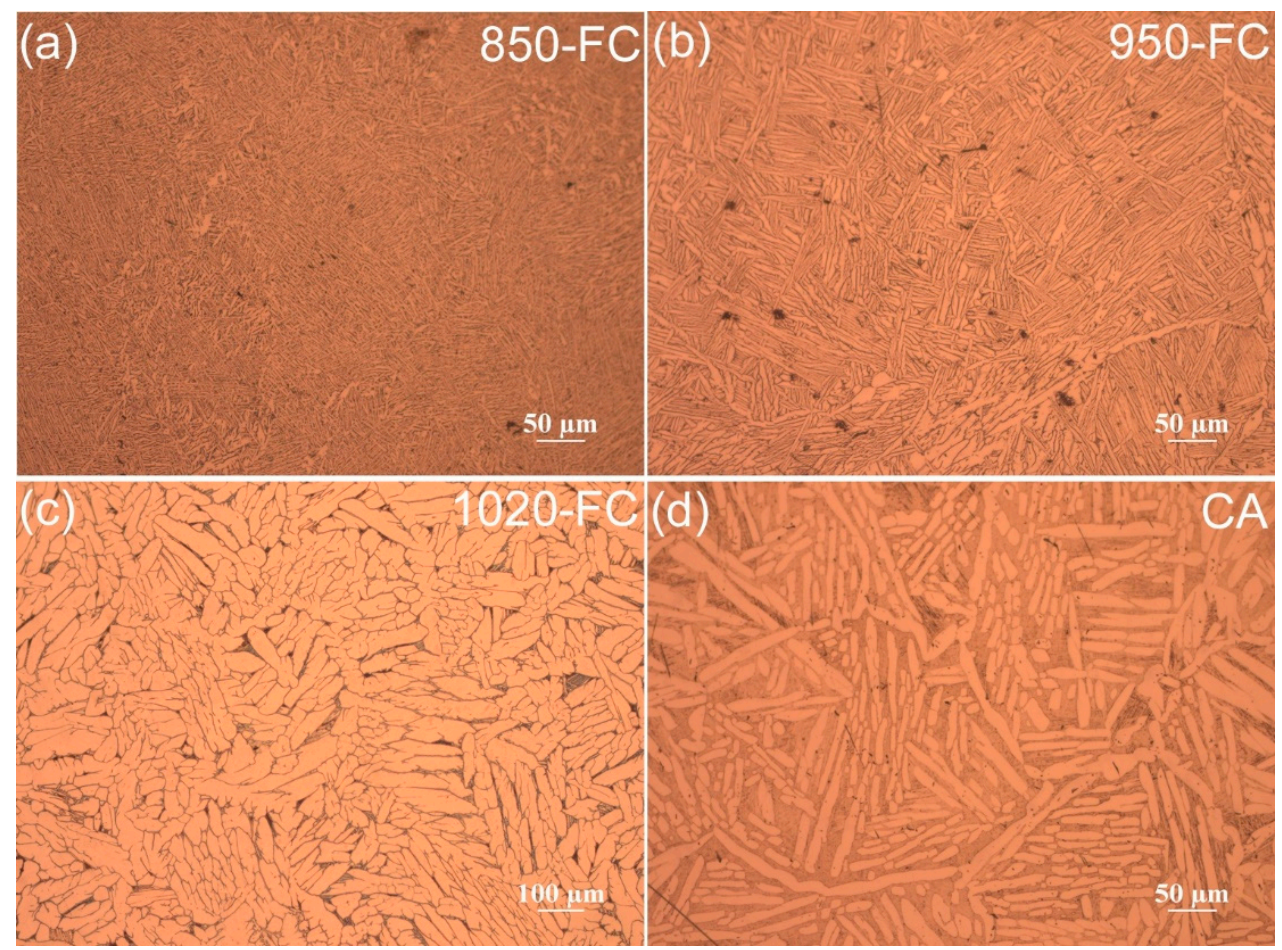

Figure 6. OM images showing the $\alpha+\beta$ structure of Ti64: (a) 850-FC, (b) 950-FC, (c) 1020-FC and (d) CA samples. 

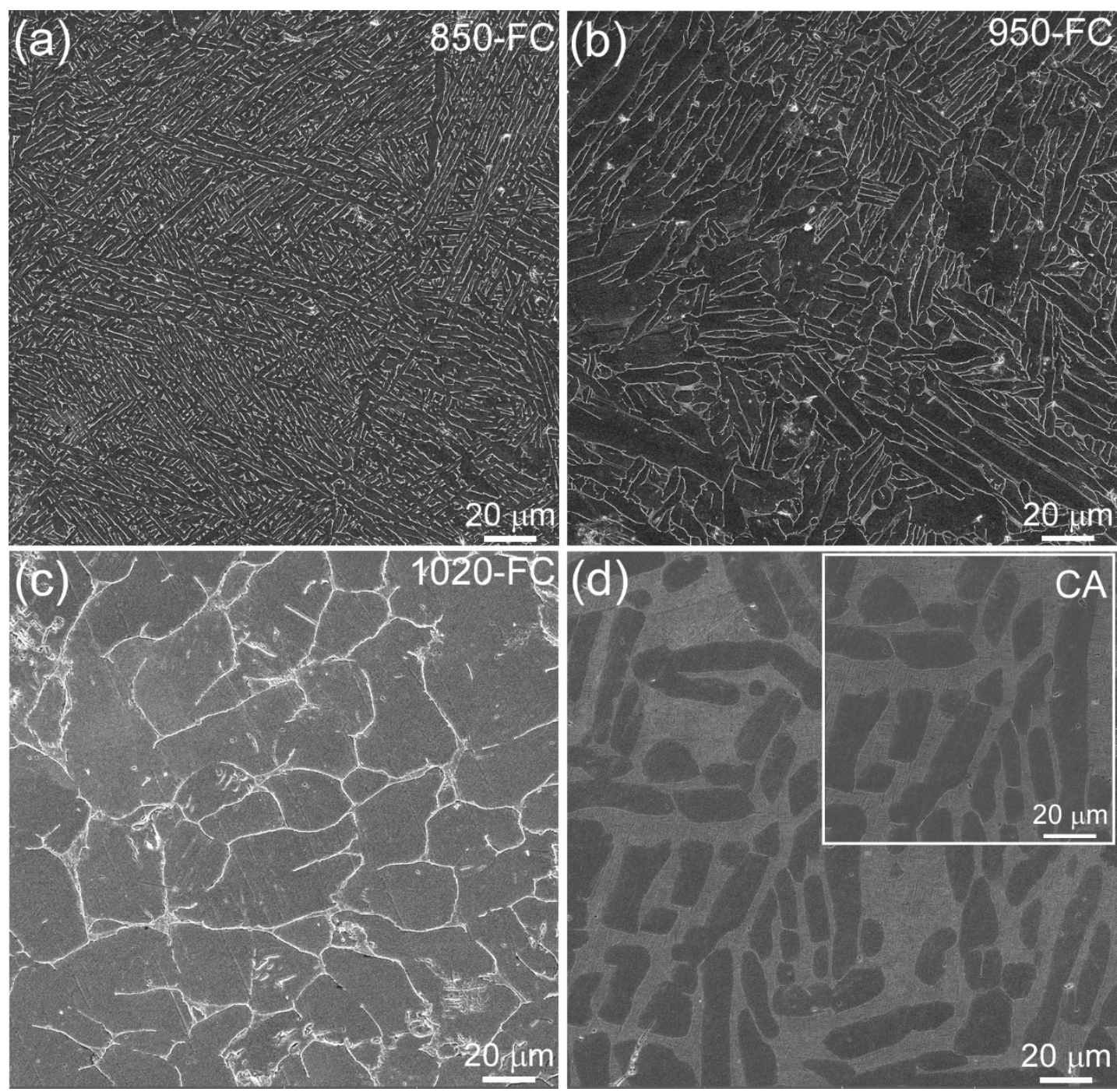

Figure 7. SEM images showing the heat-treated Ti64 specimens for: (a) 850-FC, (b) 950-FC, (c) 1020-FC and (d) CA samples.

Figure 8 displays the OM and SEM images of Ti55531 samples subjected to two kinds of heat treatment processes. When the temperature is set below $T_{\beta}$, one can still find columnar $\beta$ grains, along which grain boundary $\alpha$ precipitates. Once the processing temperature is beyond $T_{\beta}$, the shape of $\beta$ grains transforms from columnar to equiaxial. Previous references have demonstrated that a heat treatment temperature lower than $T_{\beta}$ prompted the precipitation of $\alpha$ phase, which would impede the growth of $\beta$ grain boundaries $[19,20]$. As for the processing temperature higher than $T_{\beta}$, the columnar grains were driven to become equiaxed due to the combination of Plateau-Rayleigh instability and the surface tension reduction in grain boundary surface area [30]. After $\alpha \beta$-STA, the metastable $\beta$ structure converted to a bimodal structure with equiaxed $\alpha_{\mathrm{p}}$ and acicular $\alpha_{\mathrm{s}}$ phases (see Figure 8c). This phenomenon is similar to our previous study of post-SLM-treated Ti55531 alloy [15]. In addition, a bi-lamellar structure was observed in the BASCA sample, which is composed of lamellar $\alpha_{\mathrm{p}}$ and acicular $\alpha_{\mathrm{s}}$ phases, as shown in Figure $8 \mathrm{~d}$. 

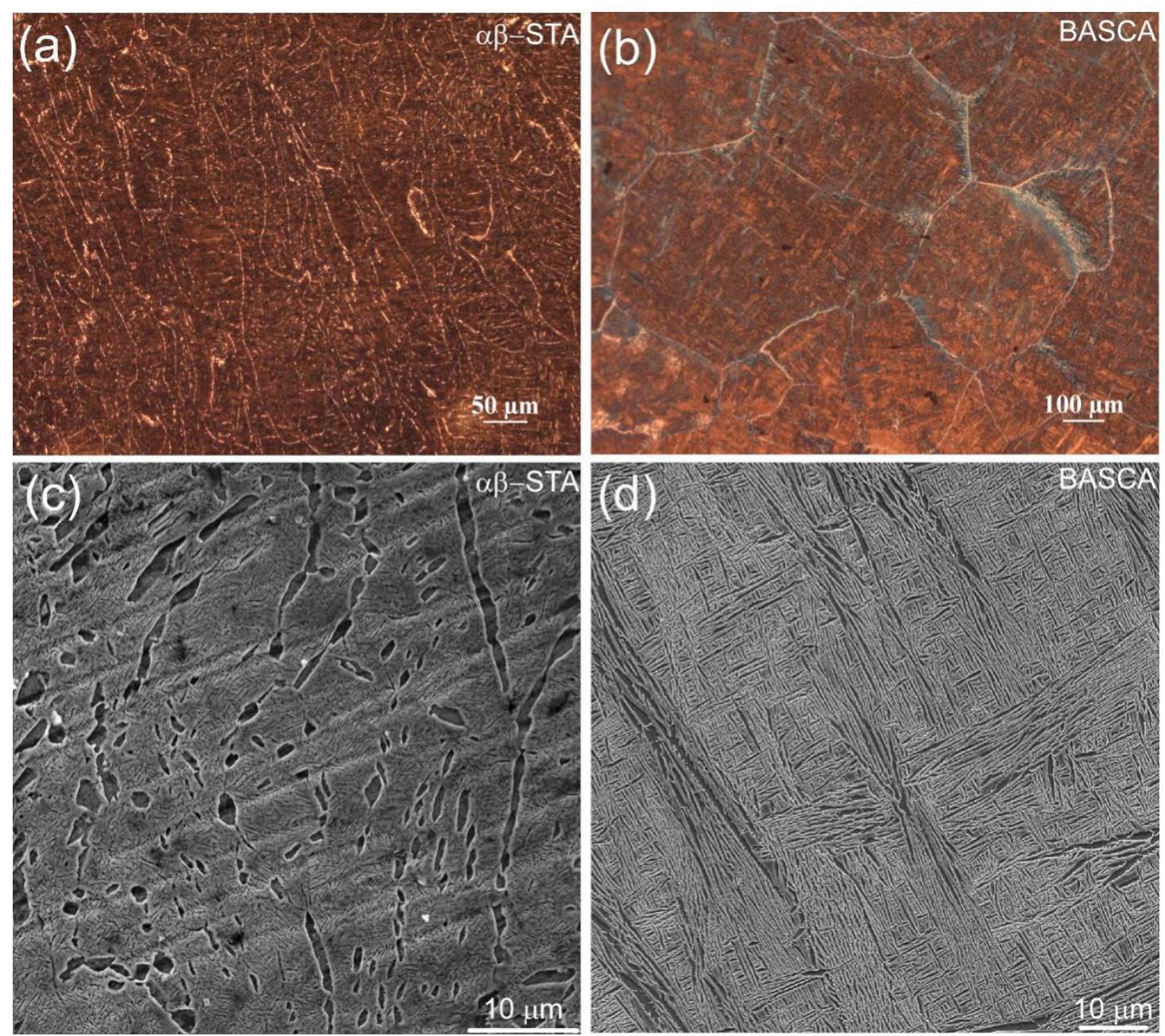

Figure 8. OM images of post-heat-treated Ti55511 alloy for: (a) $\alpha \beta$-STA and (b) BASCA. (c,d) are the corresponding SEM images.

\subsection{Mechanical Property}

The results of tensile and fracture toughness of Ti64 and Ti55511 are listed in Table 2. The representative engineering stress-strain curves of Ti64 and Ti55511 alloys are presented in Figure 9. The as-built Ti64 alloy exhibited a relatively high YS of $1065 \pm 6.8 \mathrm{MPa}$ with a limited EL of $6.1 \% \pm 0.8 \%$ due to martensite structure. Nevertheless, the ductility is distinctly improved after various batches of heat treatments. The Ti64 alloys experience monotonic reduction in strength and raise in EL with the increment of the temperature of heat treatment, e.g., the YS decreases from $943 \pm 5.2 \mathrm{MPa}$ (after 850-FC) to $742 \pm 13.5 \mathrm{MPa}$ (after 1020-FC), while EL is contrarily increased in the latter. It complies with the strengthductility trade-off theory in metallic materials. Excellent combination of strength and ductility is found in the CA sample with a bimodal structure, showing a YS of $1054 \pm 9.6 \mathrm{MPa}$ comparable to that of the SLM-fabricated sample and a doubled EL of $9.8 \% \pm 1.8 \%$. Among three FC samples, 950-FC is the highest in $\mathrm{K}_{\mathrm{IC}}$ as $90.8 \pm 2.1 \mathrm{MPa} \cdot \mathrm{m}^{1 / 2}$, followed by that of $850-\mathrm{FC}$ as $84.9 \pm 0.4 \mathrm{MPa} \cdot \mathrm{m}^{1 / 2}$ and 1020-FC as $58.7 \pm 4.6 \mathrm{MPa}^{1 / 2} \mathrm{~m}^{1 / 2}$, with coarse $\alpha$ lath. Besides, the $\mathrm{K}_{\mathrm{IC}}$ is $80.0 \pm 3.3 \mathrm{MPa} . \mathrm{m}^{1 / 2}$ for the CA sample. 
Table 2. The room temperature tensile properties and fracture toughness of Ti64 and Ti55511.

\begin{tabular}{cccccc}
\hline Alloy & Sample & YS (MPa) & UTS (MPa) & EL (\%) & K $_{\text {IC }} \mathbf{~ ( M P a . m ~}^{\mathbf{1 / 2}} \mathbf{)}$ \\
\hline \multirow{5}{*}{ Ti64 } & As-built & $1065 \pm 6.8$ & $1152 \pm 11.3$ & $6.1 \pm 0.8$ & - \\
& 850-FC & $943 \pm 5.2$ & $989 \pm 6.1$ & $10.2 \pm 0.1$ & $84.9 \pm 0.4$ \\
& 950-FC & $835 \pm 3.8$ & $887 \pm 7.1$ & $11.9 \pm 0.1$ & $90.8 \pm 2.1$ \\
& $1020-F C$ & $742 \pm 13.5$ & $839 \pm 6.2$ & $15.3 \pm 0.3$ & $58.7 \pm 4.6$ \\
& CA & $1054 \pm 9.6$ & $1196 \pm 10.2$ & $9.8 \pm 1.8$ & $80.0 \pm 3.3$ \\
\hline \multirow{2}{*}{ Ti55511 } & As-built & $789 \pm 1.9$ & $799 \pm 2.5$ & $15.9 \pm 0.3$ & - \\
& $\alpha \beta-S T A$ & $1195 \pm 10.3$ & $1245 \pm 9.9$ & $7.8 \pm 0.5$ & $64 \pm 2.1$ \\
& BASCA & $1295 \pm 8.7$ & $1320 \pm 7.5$ & $5.5 \pm 0.1$ & $70.0 \pm 2.2$ \\
\hline
\end{tabular}
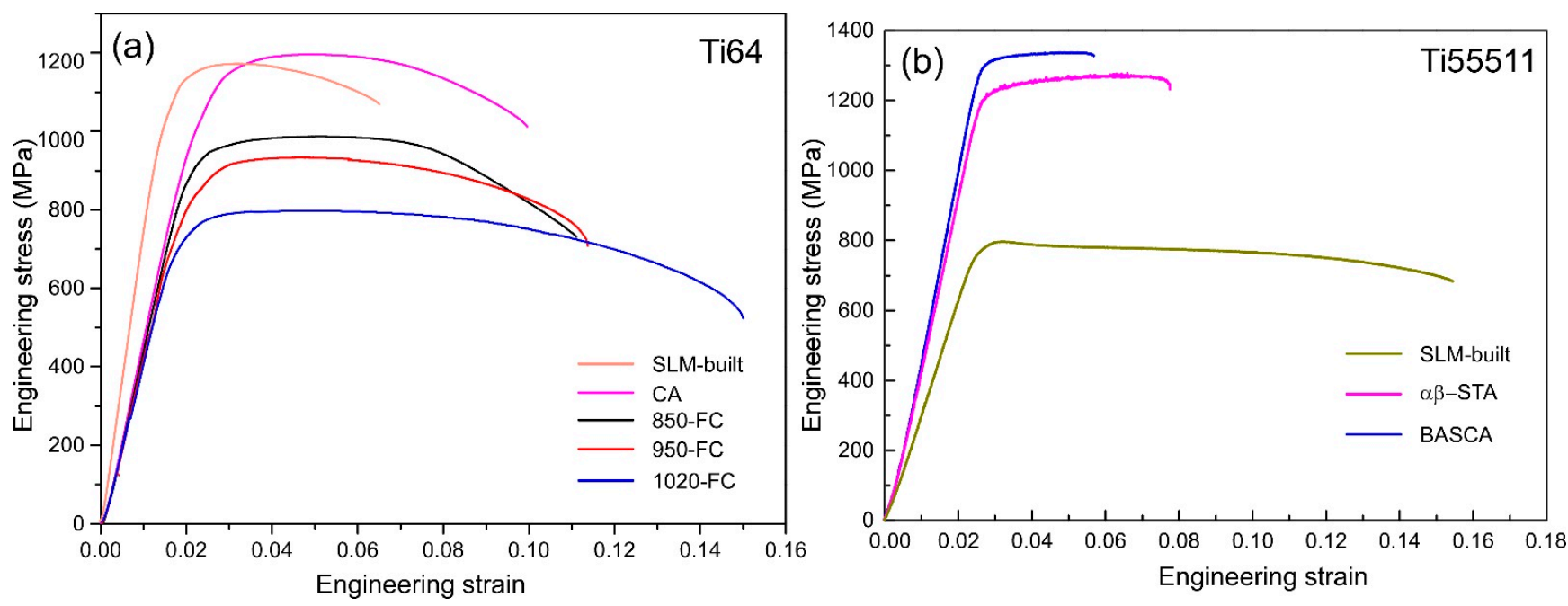

Figure 9. Representative engineering stress-strain curves of (a) Ti64 and (b) Ti55511.

The as-built Ti55511 sample shows an inferior YS of $789 \pm 1.9 \mathrm{MPa}$ with an EL as high as $15.9 \% \pm 0.3 \%$, which is typical in the metastable $\beta$-dominated titanium alloys lacking a high-strength preferred $\alpha$ phase. As is well accepted, Ti55511 is classified as a high-strength, high-temperature titanium alloy with a YS normally exceeding $1050 \mathrm{MPa}$ or higher once the heat treatment process is applied. A satisfying overall mechanical performance with the combination of YS as $1195 \pm 10.3 \mathrm{MPa}, \mathrm{EL}$ as $7.8 \% \pm 0.5 \%$ and $\mathrm{K}_{\mathrm{IC}}$ as $64 \pm 2.1 \mathrm{MPa} \cdot \mathrm{m}^{1 / 2}$ is obtained after the treatment of $\alpha \beta$-STA. In the case of the BASCA sample, an even higher YS as $1295 \pm 8.7 \mathrm{MPa}$ is achieved, while the EL and $\mathrm{K}_{\mathrm{IC}}$ are $5.5 \% \pm 0.1 \%$ and $70.0 \pm 2.2 \mathrm{MPa}^{1 / 2}$, respectively.

Figure 10 illuminates the morphological details with respect to the cross-sectional fractures of the Ti64 and Ti55511 samples for tensile tests. Obviously, all the Ti64 samples after heat treatment processes exhibit a vast number of dimples, implying a fracture mode based on the aggregation of micropores. Similar distribution of dimples was also observed in the Ti55511 sample after $\alpha \beta$-STA. In BASCA-treated Ti55511, however, a mixed dimpled and faceted fracture mode was recognized. 

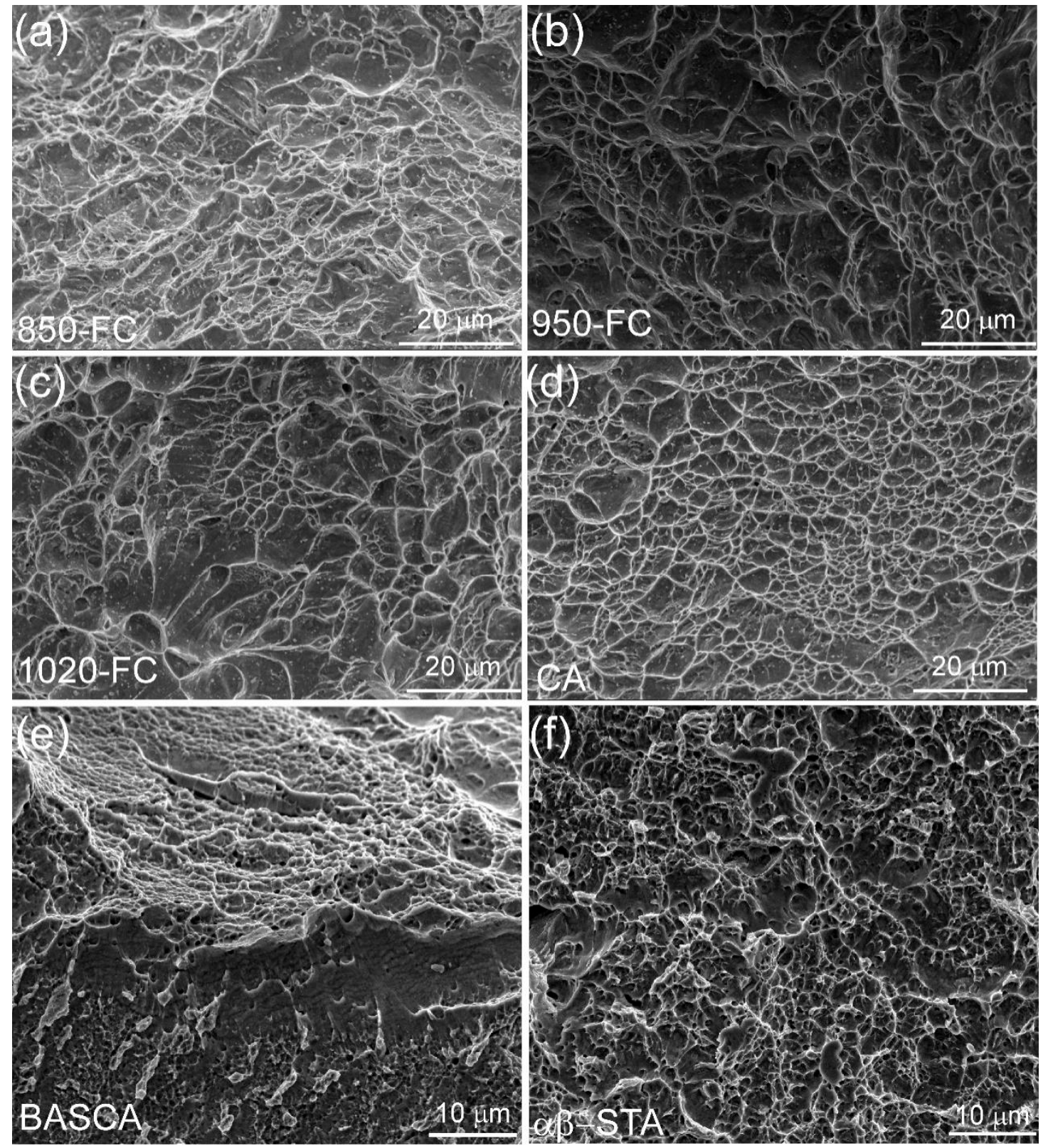

Figure 10. High magnification fractographs of samples (a) 850-FC, (b) 950-FC, (c) 1020-FC, (d) CA, (e) BASCA and (f) $\alpha \beta$-STA samples.

\section{Discussion}

\subsection{Effect of Heat Treatment on the Microstructure}

Both Ti64 and Ti55511 are the alloys open for further heat treatment, during which the diffusion-controlled phase transformation is about to take place. Hence, the microstructural properties of these titanium alloys are quite sensitive to the parameters of heat treatments, including but not limited to, temperature, cooling rate, etc. For Ti64, the content of $\alpha+\beta$ is affected by the heat treatment temperature below $\mathrm{T}_{\beta}$, while the cooling rate determines the width of $\alpha$ lath, either the heat treatment temperature is above or beneath $\mathrm{T}_{\beta}$. The SLMbuilt Ti64 contains lots of $\alpha^{\prime}$ grain boundaries on which $\alpha$ phases are prone to precipitate during the heat treatment process. Meanwhile, vanadium atoms are ejected to newly generated $\alpha$ grain boundaries so that $\beta$ phases are formed near the precipitated $\alpha$ phase boundaries $[19,31]$. In the region of $\alpha+\beta$, the elementary distribution effect becomes even more significant. Once the holding temperature reaches $850^{\circ} \mathrm{C}, \alpha^{\prime}$ phases decompose to 
$\alpha+\beta$ phases as the decomposition temperature of $\alpha^{\prime}\left(730^{\circ} \mathrm{C}\right)$ is exceeded [19]. The dwelling process at $950{ }^{\circ} \mathrm{C}$ gives rise to the further broadening of $\alpha$ lath width and the reduction in the content of $\beta$ phases. Vrancken et al. [20] pointed out that the less population of $\alpha$ nucleation sites prompted the coarsening of $\alpha$ laths before they could interact with each other. The relatively slow cooling rate of furnace cooling will lead to the formation of $\alpha$ colony. Pure $\beta$ is all one can find above $\mathrm{T}_{\beta}$, while $\alpha$ colony precipitations are recognized along the grain boundaries of prior $\beta$ once the temperature is lower than $T_{\beta}$, which is the well-known Widmanstätten structure. As for the 1020-FC sample, the rapid increase in width drives the $\alpha$ laths to be equiaxed, as shown in Figure 7c. In general, the migration of $\alpha$ grain boundaries will be impeded if the adjacent $\alpha$ laths are different in the growing direction. The impeding effect shall be lessened with a furnace cooling process from a temperature over $\mathrm{T}_{\beta}$, considering that it is possible for the $\alpha$ laths to simultaneously grow in different directions if the interfacial energy is markedly reduced at a relatively higher temperature. The sample after CA treatment is featured by bimodal structure that is a result of the massive substructures in $\alpha^{\prime}$ phases. Due to the low cooling and heating rates during the cyclic heat treatments, these substructures are to be decomposed based on the mechanism of thermal grooving and boundary splitting, crushing the generated $\alpha$ laths into equiaxed or stripe-shaped $\alpha_{\mathrm{p}}$ phases [21]. Ultimately, the bimodal structure is obtained after a consequent air cooling (AC) process.

The metastable $\beta$ structure in as-fabricated Ti55511 is regarded as an ideal prototype for post-heat treatments. Both the works of Deng et al. [15] and Schwab et al. [14] demonstrated the existence of metastable $\beta$ structure in SLM-prepared metastable $\beta$ titanium alloys. Owing to the relevant factors such as melt convection and surface tension in molten pool, metastable $\beta$ grains contain a large number of substructures or sub-boundaries, which offer preferred nucleation sites for the $\alpha$ phases during the post-heat treatment process. After $\alpha \beta$-STA, bimodal structure is formed. When the sample is heated at $830^{\circ} \mathrm{C}$ for solid solution, $\alpha_{\mathrm{p}}$ is prone to precipitate near $\beta$ grain boundaries and form $\alpha_{\mathrm{GB}}$. At the same time, the internal substructures are also available precipitation sites for $\alpha_{\mathrm{p}}$ phases. Coarse $\alpha_{\mathrm{p}}$ phases are finally obtained after a $1.5 \mathrm{~h}$ dwelling process. According to the literature, the stability of retained $\beta$ phases is fairly high around $\alpha_{p}$ phases, because the precipitation of $\alpha_{p}$ phases is proceeded on the premise of the consumption of $\alpha$ stabilizers in $\beta$ matrix as well as the enrichment of $\beta$ stabilizers [32]. Considering that the precipitation kinetics of $\alpha$ phase are relatively low at an aging temperature of $600^{\circ} \mathrm{C}$, only fine secondary $\alpha$ phases are precipitated afterwards. In the BASCA sample with a typical bi-lamellar structure, the $\alpha_{G B}$ layer is firstly precipitated when the temperature is below $T_{\beta}$. Whereafter, intergranular $\alpha_{\mathrm{p}}$ colonies (aka the Widmanstätten colonies) are found around $\alpha_{\mathrm{GB}}$. Moreover, Figure $8 \mathrm{c}$ also exhibits the internal growth of $\alpha_{\mathrm{p}}$ plates within $\beta$ grains. Eventually, the rapid cooling process of solution treatment enables the preservation of some retained $\beta$ phases between $\alpha_{\mathrm{p}}$ plates, in which fine acicular $\alpha_{\mathrm{s}}$ phases are apt to nucleate during the subsequent aging process.

\subsection{Effect of Heat Treatment on Mechanical Properties}

The mechanical performances of titanium alloys are highly related to the content, morphology and size of the $\alpha$ phase. As-fabricated Ti64 alloy contains abundant martensites featured by the properties of hard, brittle and extremely low deformability, which therefore results in the nature of high strength and poor ductility. For the case of Ti64, the size of $\alpha$ lath rises with the increment of furnace cooling temperature. The excellent EL of 1020-FC should be attributed to the substantial room for the dislocation slipping of large $\alpha$ laths during tensile stress, while 850-FC possesses the highest strength value with a relatively low ductility owing to the massive fine $\alpha$ laths. Titanium alloys with an ideal bimodal structure usually exhibit excellence in the combination of strength and ductility. Besides, fine $\alpha_{\mathrm{s}}$ with the impossibility of large deformation is another kind of strengthening phase, which forms a number of $\alpha_{s} / \beta_{r}$ interfaces with adjacent $\beta_{\mathrm{r}}$ so that the dislocation glide is effectively hindered [16]. Hence, the Ti64 and Ti55511 alloys with a bimodal structure 
show the best overall mechanical performance. In the BASCA sample, however, a higher strength but poorer EL than those of the one with a bimodal structure is obtained because of the inferior coordination in the deformation of $\alpha_{P}$ lath compared with the equiaxed $\alpha_{P}$ phase.

Two major factors dominate the $\mathrm{K}_{\mathrm{IC}}$ of titanium alloys, crack path tortuosity and material plastic deformation along the crack path [32]. It has been proven that the thickening of $\alpha$ lamella could prevent the crack propagation as the cracks have to keep varying directions to pass through thick lamellae and consume much more energy during the deflection of cracks. As a result, $\mathrm{K}_{\mathrm{IC}}$ is higher in 950-FC than in 850-FC. With the clue that the $\alpha$ phase in 1020-FC is relatively large in size and equiaxed in shape, we should assume a good deformation compatibility in this sample and draw a conclusion that the $\mathrm{K}_{\mathrm{IC}}$ of 1020-FC is mainly determined by the extent of plastic deformation of $\alpha$ phase. As the equiaxed $\alpha$ phases are easy to yield during deformation and produce numerous slip bands, it will be easy for cracks to pass through. Plenty of works have demonstrated the soft primary $\alpha$ phases as the initiation sites and propagation channels for cracks in bimodal structures [16,32]. Since soft $\alpha_{\mathrm{P}}$ phases are likely to deform plastically and create slip bands which provide cracks with favorable pathways, it makes sense that the $\mathrm{K}_{\mathrm{IC}}$ of the CA Ti64 sample is lower than that of the ones with lamellar structures. Similarly, in Ti55511 samples, the BASCA samples with bi-lamellar structures exhibit superior $\mathrm{K}_{\mathrm{IC}}$ values compared to those with bimodal structures.

Although heat treatment is an extra step after the SLM process, the overall manufacturing efficiency and the geometry of as-built components will not be affected. More importantly, heat treatment is a favorable way to eliminate the non-equilibrium microstructure of SLM-fabricated $\alpha+\beta$ and metastable $\beta$ Ti-alloys, and the mechanical properties of these alloys have also been greatly improved. The residual stress can also be relieved by heat treatment.

\section{Conclusions}

In this work, the effects of heat treatment on microstructural evolution of SLMfabricated Ti64 and Ti55511 alloys were systematically investigated. The relationships between microstructure and tensile properties and fracture toughness were established. The key conclusions are as follows:

1. Owing to the high solidification rate during the SLM process, the as-fabricated Ti64 alloy exhibited a martensite microstructure, while the Ti55511 alloy possessed a metastable $\beta$ structure.

2. After heat treatment, these non-equilibrium structures were converted into $\alpha+\beta$ structure. For Ti64 alloy, the width of $\alpha$ lamella increased with the annealing temperature. When the heat treatment temperature is above the $T_{\beta}$, the morphology of obtained $\alpha$ phase is equiaxed. Moreover, a CA treatment has successfully induced a bimodal structure in SLM-fabricated Ti64.

3. In the case of Ti55511 alloy, bimodal and lamellar microstructures were obtained after the $\alpha \beta$-STA and BASCA heat treatments, respectively. The lamellar structure showed higher strength (YS of $1295 \pm 8.7 \mathrm{MPa}$ ) and fracture toughness $\left(70.0 \pm 2.2 \mathrm{MPa} . \mathrm{m}^{1 / 2}\right)$, and the equiaxed structure exhibited a relatively higher ductility (EL of $7.8 \% \pm 0.5 \%$ ) but lower strength (YS of $1195 \pm 10.3 \mathrm{MPa}$ ) and fracture toughness $\left(64 \pm 2.1 \mathrm{MPa} . \mathrm{m}^{1 / 2}\right)$.

4. Ti64 and Ti55511 alloys with a bimodal structure have a good combination of ductility (EL of $9.8 \% \pm 1.8 \%$ ) and strength (YS of $1054 \pm 9.6 \mathrm{MPa}$ ). The tensile property is dependent on the size and morphology of $\alpha$ phase. Fracture toughness of Ti64 and Ti55511 were controlled by the crack path tortuosity and material plastic deformation.

Author Contributions: Conceptualization, H.D. and X.C.; methodology, H.B. and T.L.; software, X.L.; validation, X.C. and T.L.; formal analysis, H.B., X.Q. and H.D.; investigation, H.B. and L.C.; resources, X.C. and D.Z.; data curation, H.B.; writing-original draft preparation, H.B.; writingreview and editing, H.B.; visualization, X.C.; supervision, X.C. and T.L.; project administration, X.C. 
and T.L.; funding acquisition, X.C. All authors have read and agreed to the published version of the manuscript.

Funding: This work was supported by Department of Science and Technology of Sichuan Province under grant number (No. 2018GZ0493).

Institutional Review Board Statement: Not applicable.

Informed Consent Statement: Not applicable.

Data Availability Statement: Not applicable.

Conflicts of Interest: The authors declare no conflict of interest.

\section{References}

1. Yap, C.Y.; Chua, C.K.; Dong, Z.L.; Liu, Z.H.; Zhang, D.Q.; Loh, L.E.; Sing, S.L. Review of selective laser melting: Materials and applications. Appl. Phys. Rev. 2015, 2, 041101-041121. [CrossRef]

2. Zhang, J.; Song, B.; Wei, Q.; Bourell, D.; Shi, Y. A review of selective laser melting of aluminum alloys: Processing, microstructure, property and developing trends. J. Mater. Sci. Technol. 2019, 35, 270-284. [CrossRef]

3. Frazier, W.E. Metal Additive Manufacturing: A Review. J. Mater. Eng. Perform. 2014, 23, 1917-1928. [CrossRef]

4. Cao, S.; Chen, Z.; Lim, C.V.S.; Yang, K.; Jia, Q.; Jarvis, T.; Tomus, D.; Wu, X.J.J. Defect, microstructure, and mechanical property of Ti64 alloy fabricated by high-power selective laser melting. JOM 2017, 69, 2684-2692. [CrossRef]

5. Mertová, K.; Džugan, J.; Roudnická, M.; Daniel, M.; Vojtěch, D.; Seifi, M.; Lewandowski, J.J. Build Size and Orientation Influence on Mechanical Properties of Powder Bed Fusion Deposited Titanium Parts. Metals 2020, 10, 1340. [CrossRef]

6. Wang, P.; Li, H.; Prashanth, K.; Eckert, J.; Scudino, S. Selective laser melting of Al-Zn-Mg-Cu: Heat treatment, microstructure and mechanical properties. J. Alloy. Compd. 2017, 707, 287-290. [CrossRef]

7. Martin, J.H.; Yahata, B.D.; Hundley, J.M.; Mayer, J.A.; Schaedler, T.A.; Pollock, T.M. 3D printing of high-strength aluminium alloys. Nature 2017, 549, 365-369. [CrossRef] [PubMed]

8. Wang, Y.M.; Voisin, T.; McKeown, J.T.; Ye, J.; Calta, N.P.; Li, Z.; Zeng, Z.; Zhang, Y.; Chen, W.; Roehling, T.T.; et al. Additively manufactured hierarchical stainless steels with high strength and ductility. Nat. Mater. 2018, 17, 63-71. [CrossRef] [PubMed]

9. Wang, Z.; Palmer, T.A.; Beese, A.M. Effect of processing parameters on microstructure and tensile properties of austenitic stainless steel 304L made by directed energy deposition additive manufacturing. Acta Mater. 2016, 110, 226-235. [CrossRef]

10. Barriobero-Vila, P.; Gussone, J.; Stark, A.; Schell, N.; Haubrich, J.; Requena, G. Peritectic titanium alloys for 3D printing. Nat. Commun. 2018, 9, 3426-3434. [CrossRef] [PubMed]

11. Antonysamy, A.A.; Meyer, J.; Prangnell, P.B. Effect of build geometry on the $\beta$-grain structure and texture in additive manufacture of Ti6Al4V by selective electron beam melting. Mater. Charact. 2013, 84, 153-168. [CrossRef]

12. Hebert, R.J. Metallurgical aspects of powder bed metal additive manufacturing. J. Mater. Sci. 2016, 51, 1165-1175. [CrossRef]

13. Thijs, L.; Verhaeghe, F.; Craeghs, T.; Humbeeck, J.V.; Kruth, J.-P. A study of the microstructural evolution during selective laser melting of Ti-6Al-4V. Acta Mater. 2010, 58, 3303-3312. [CrossRef]

14. Schwab, H.; Palm, F.; Kühn, U.; Eckert, J. Microstructure and mechanical properties of the near-beta titanium alloy Ti-5553 processed by selective laser melting. Mater. Des. 2016, 105, 75-80. [CrossRef]

15. Deng, H.; Qiu, W.; Cao, S.; Chen, L.; Hu, Z.; Wei, Y.; Xia, Z.; Zhou, L.; Cui, X.; Tang, J.; et al. Heat-treatment induced microstructural evolution and enhanced mechanical property of selective laser melted near $\beta$ Ti-5Al-5Mo-5V-3Cr-1Zr alloy. J. Alloy. Compd. 2021, 858, 158351-158361. [CrossRef]

16. Li, Z.Y.; Wu, G.Q.; Huang, Z. Relationships between microstructure and mechanical properties of Ti-5Al-5Mo-5V-3Cr-1Zr alloy. Mater. Res. Express 2018, 5, 036518-036527. [CrossRef]

17. Lütjering, G. Influence of processing on microstructure and mechanical properties of $(\alpha+\beta)$ titanium alloys. Mater. Sci. Eng. A 1998, 243, 32-45. [CrossRef]

18. Cao, S.; Chu, R.; Zhou, X.; Yang, K.; Jia, Q.; Lim, C.V.S.; Huang, A.; Wu, X. Compounds. Role of martensite decomposition in tensile properties of selective laser melted Ti64. J. Alloy. Compd. 2018, 744, 357-363. [CrossRef]

19. Zhang, X.-Y.; Fang, G.; Leeflang, S.; Böttger, A.J.; Zadpoor, A.A.; Zhou, J. Effect of subtransus heat treatment on the microstructure and mechanical properties of additively manufactured Ti64 alloy. J. Alloy. Compd. 2018, 735, 1562-1575. [CrossRef]

20. Vrancken, B.; Thijs, L.; Kruth, J.-P.; Van Humbeeck, J. Heat treatment of Ti6Al4V produced by Selective Laser Melting: Microstructure and mechanical properties. J. Alloy. Compd. 2012, 541, 177-185. [CrossRef]

21. Sabban, R.; Bahl, S.; Chatterjee, K.; Suwas, S. Globularization using heat treatment in additively manufactured Ti64 for high strength and toughness. Acta Mater. 2019, 162, 239-254. [CrossRef]

22. Carlton, H.D.; Klein, K.D.; Elmer, J.W. Evolution of microstructure and mechanical properties of selective laser melted Ti-5Al-5V5Mo-3Cr after heat treatments. Sci. Technol. Weld. Join. 2019, 24, 465-473. [CrossRef]

23. Li, F.; Qi, B.; Zhang, Y.; Guo, W.; Peng, P.; Zhang, H.; He, G.; Zhu, D.; Yan, J. Effects of Heat Treatments on Microstructures and Mechanical Properties of Ti6Al4V Alloy Produced by Laser Solid Forming. Metals 2021, 11, 346. [CrossRef] 
24. Ratochka, I.V.; Mishin, I.P.; Lykova, O.N. Structural Evolution and Mechanical Properties of a VT22 Titanium Alloy Under High-Temperature Deformation. Russ. Phys. J. 2016, 59, 1-6. [CrossRef]

25. Liu, C.M.; Tian, X.J.; Wang, H.M.; Liu, D. Obtaining bimodal microstructure in laser melting deposited Ti-5Al-5Mo-5V-1Cr-1Fe near $\beta$ titanium alloy. Mater. Sci. Eng. A 2014, 609, 177-184. [CrossRef]

26. Sadeghpour, S.; Abbasi, S.; Morakabati, M.; Bruschi, S. Correlation between alpha phase morphology and tensile properties of a new beta titanium alloy. Mater. Des. 2017, 121, 24-35. [CrossRef]

27. Qazi, J.; Rahim, J.; Fores, F.S.; Senkov, O.; Genc, A. Phase transformations in Ti64-xH alloys. Metall. Mater. Trans. A 2001, 32, 2453-2463. [CrossRef]

28. Lütjering, G.; Williams, J.C. Titanium; Springer Science \& Business Media: Berlin/Heidelberg, Germany, 2007 ; pp. 152-160.

29. Vrancken, B.; Thijs, L.; Kruth, J.P.; Van Humbeeck, J. Microstructure and mechanical properties of a novel $\beta$ titanium metallic composite by selective laser melting. Acta Mater. 2014, 68, 150-158. [CrossRef]

30. Zafari, A.; Lui, E.W.; Xia, K. Deformation-free geometric recrystallisation in a metastable $\beta$-Ti alloy produced by selective laser melting. Mater. Res. Lett. 2020, 8, 117-122. [CrossRef]

31. Tan, X.; Kok, Y.; Tan, Y.J.; Descoins, M.; Mangelinck, D.; Tor, S.B.; Leong, K.F.; Chua, C.K. Graded microstructure and mechanical properties of additive manufactured Ti64 via electron beam melting. Acta Mater. 2015, 97, 1-16. [CrossRef]

32. Wu, C.; Zhan, M. Microstructural evolution, mechanical properties and fracture toughness of near $\beta$ titanium alloy during different solution plus aging heat treatments. J. Alloy. Compd. 2019, 805, 1144-1160. [CrossRef] 